\title{
A rede de cuidados do Sistema Único de Saúde à saúde das pessoas com deficiência
}

\author{
The Brazilian Health System integrated health service network for people with disabilities \\ La rede integrada de servicios de salud del Sistema Brasileño de Salud para personas com discapacidads
}

Mariana Fernandes Campos ${ }^{(a)}$

Luiz Augusto de Paula Souza(b)

Vera Lúcia Ferreira Mendes(c)

A saúde da pessoa com deficiência foi uma agenda preterida no Sistema Único de Saúde (SUS). Não há exagero nessa afirmação, pois, geralmente, as iniciativas nesse campo eram pontuais, muitas vezes parcelares, e sem nexos com os princípios de integralidade, equidade, universalidade e acesso qualificado e universal à saúde.

Entre outros exemplos, serviços isolados e portarias, como as de Saúde Auditiva (Portaria 587/SAS/MS, de 7 de outubro de 2004), Assistência à Pessoa com Deficiência Física (Portaria no 818/GM/MS, de 5 de junho de 2001) e Assistência à Pessoa com Deficiência Visual (Portaria no 3.128/GM/MS, de 24 de dezembro de 2008), não lograram uma articulação consistente com os pontos e níveis de atenção à saúde do SUS; o caráter fragmentário e a pouca eficácia desse tipo de medida, em termos de equacionamento das complexas problemáticas de saúde das pessoas com deficiência, corroboram, para dizer o mínimo, o caráter lateral ou secundário que a saúde da pessoa com deficiência ocupou no SUS até recentemente.

Diante da insuficiência da ação do Estado brasileiro, e antes mesmo da existência do SUS, a sociedade civil, ao menos em parte, assumiu os cuidados em saúde (também de educação e assistência social) da população com deficiência, por meio de: movimentos sociais de deficientes; associações de amigos e parentes; e, também, pela ação de entidades filantrópicas, religiosas e/ou de mercado. Ao longo de décadas, algumas dessas iniciativas constituíram qualidade e se tornaram referências na assistência à saúde de determinadas deficiências; outras tantas convivem com visões assistencialistas, dificuldades técnicas e problemas de financiamento.

Em todo caso e apesar da importância histórica das iniciativas da sociedade civil, o Brasil acabou produzindo uma miríade de abordagens dispersas, frequentemente subfinanciadas e sem um sistema de regulação minimamente adequado, o que impede, por exemplo, a identificação de boas práticas e o estabelecimento de parâmetros epidemiológicos e técnico-científicos que orientem, articulem e gerem maior consistência aos cuidados à saúde dessa população.

No entanto, também é fato que, nos últimos anos, com o avanço dos movimentos sociais das pessoas com deficiência, o desenvolvimento internacional

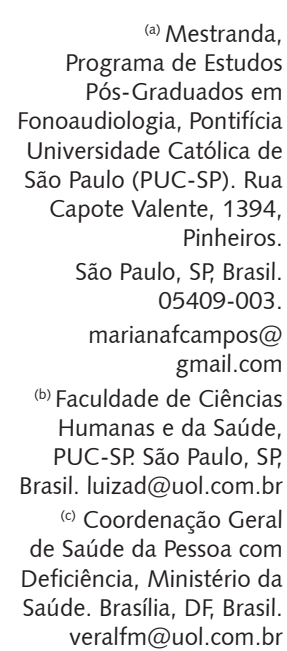


desse campo (por exemplo, Convenção Internacional sobre os Direitos da Pessoa com Deficiência, Nova York, 30 de março de 2007, da qual o Brasil é signatário) e, no Brasil, também com o incremento da agenda dos Direitos Humanos, o governo brasileiro começa a se aproximar da problemática e, de forma explícita, a Presidência da República a assume, em 2011, como prioridade de governo, lançando o Viver Sem Limite: Plano Nacional de Direitos da Pessoa com Deficiência, que envolve mais de 15 pastas ministeriais e conta com investimentos previstos da ordem de 14 bilhões de reais até 2014, em ações divididas por quatro eixos prioritários: Atenção à Saúde; Acesso à Educação; Inclusão Social; e Acessibilidade.

O Ministério da Saúde é um dos atores centrais do Plano Viver Sem Limite; e mais do que realizar ações incrementais em relação àquilo que é praticado na saúde das pessoas com deficiência, tornou estruturante essa agenda no SUS, por meio da criação da Rede de Cuidados à Saúde da Pessoa com Deficiência, na condição de rede prioritária de saúde.

O processo de formulação e implementação dessa Rede começa em 2012, com a publicação da Portaria 793, de 25 de abril de 2012, que institui a Rede de Cuidados à Saúde da Pessoa com Deficiência no âmbito do SUS.

Para o processo de implementação da Rede, o Ministério da Saúde, por meio da Coordenação Geral de Saúde da Pessoa com Deficiência, viajou o Brasil inteiro para elaborar uma série de orientações, normativas, instrutivos e materiais de referência ${ }^{(d)}$ a partir da discussão e da definição dos princípios e diretrizes da Rede com gestores e profissionais da saúde, movimentos sociais e pesquisadores.

A implicação de tais atores e a disposição em fazer uma política pública pluralista e produzida de forma ascendente, isto é, com a participação direta da sociedade, foram e são decisivas para que, de fato, a Rede de Cuidados à Saúde da Pessoa com Deficiência se consolide como conquista da cidadania brasileira, indo ao encontro da maior conquista brasileira no campo da saúde: o SUS; e se inserindo na busca pela produção qualificada de saúde, com oferta de cuidados pautada: pela integralidade da assistência; pela universalidade do acesso; pela equidade do cuidado; e pelo controle social.

Concomitantemente à instauração da atual política, objetivada pela Rede de Cuidados à Saúde da Pessoa com Deficiência, a Portaria 835, de 25 de abril de 2012, institui regras de financiamento aos estados e municípios, tanto para construir, ampliar, reformar, equipar e capacitar os profissionais de saúde das unidades de saúde envolvidas pela Rede, quanto para o custeio mensal de seus serviços nesse campo.

Financiamento adequado e contínuo é condição necessária e relevante à passagem da intenção e do discurso às práticas concretas e estruturantes. Não por acaso, portanto, essa dimensão foi cuidadosamente normatizada e de maneira simultânea à instituição da Rede. O volume de recursos orçamentários é consistente, ultrapassando a situação de aportes pontuais e/ou eventuais, que caracterizaram o financiamento federal de ações de saúde para pessoas com deficiência até 2011.

Nesse sentido, é importante mencionar que os repasses financeiros feitos pela União viabilizam a ampliação da assistência e ajudam a qualificar os serviços, franqueando, por exemplo: a contratação e a capacitação de profissionais; a incorporação de tecnologias; a qualificação dos espaços e de sua ambiência; e a indicação, concessão e manutenção de órteses, próteses e meios auxiliares de locomoção.

Naturalmente, se o financiamento adequado é necessário, a construção da

\footnotetext{
(d) O Ministério da Saúde disponibiliza online a documentação aqui citada, bem como todas as informações sobre a Rede de Cuidado à Saúde da Pessoa com Deficiência no endereço: www.saude.gov.br/ pessoacomdeficiencia
} 
(e) As habilitações são feitas para equipamentos de reabilitação já existentes, públicos ou da sociedade civil, que se disponham a integrar a lógica e cumprir os requisitos da nova política. Estes equipamentos são indicados de maneira justificada pelos Grupos Condutores da Rede de Cuidados à Saúde da Pessoa com Deficiência. Os Grupos Condutores são formados por gestores e profissionais dos estados e municípios. lógica de cuidados à saúde da pessoa com deficiência é fundamental, porque dá sentido e consistência à nova Rede. O cuidado está pensado em rede, os serviços são organizados em linhas de cuidado, em função das necessidades da população e dos arranjos territoriais. Desse modo, permite-se que a atenção em saúde esteja focada no contexto do território e dê sustentação a projetos terapêuticos singulares, ampliando as possibilidades de equidade e de cuidado integral às pessoas com deficiência.

Antes da atual política, o cuidado à saúde da pessoa com deficiência estava restrito a equipamentos de reabilitação: serviços do componente de saúde da Atenção Especializada, o que é insuficiente para as demandas de saúde da pessoa com deficiência. A nova Rede entende que os Centros de Reabilitação são necessários como pontos de atenção para ações específicas no cuidado à saúde da pessoa com deficiência, mas, também, são concebidos como espaços de articulação com os outros pontos de atenção do SUS.

A atual política define que a Rede se organiza nos seguintes componentes: Atenção Básica, Atenção Especializada e Atenção Hospitalar e de Urgência e Emergência. Os pontos de atenção desses componentes estão articulados por conjuntos de ações, de protocolos de ação e de procedimentos, que estabelecem os processos e os fluxos do cuidado entre os componentes e seus pontos de atenção.

A Rede institui, no componente de Atenção Especializada, novos espaços e outra lógica na organização da reabilitação: Centros Especializados de Reabilitação - CER. Os CERs são construídos ou habilitados ${ }^{(e)}$ para atender duas, três ou as quatro modalidades de reabilitação (auditiva, física, intelectual e visual), rompendo com a lógica da reabilitação por modalidade de deficiência fechada sobre si mesma. Para cada tipo de CER é definida uma equipe interdisciplinar obrigatória, que varia conforme o tipo de CER e as modalidades de deficiência atendidas pelo serviço.

A Rede de Cuidados à Pessoa com Deficiência, em suma, cria condições de tratamento em reabilitação a partir do CER, que, na condição de nó da Rede, articula os outros componentes e pontos de atenção, sejam eles públicos, comunitários ou privados. O CER é, portanto, estratégico na qualificação, regulação e criação de padrões mínimos para os cuidados às pessoas com deficiência, inclusive, em termos de acolhimento de diferenças e de humanização dos cuidados. Daí sua centralidade na nova Rede.

Vale destacar ainda que, inserida nas ações da Atenção Especializada, a Oficina Ortopédica é um ponto de atenção importante no processo de reabilitação, por isso integra a rede e é normatizada na atual política. É na Oficina Ortopédica que se produzem e se realizam: confecção, adaptação e manutenção de Órteses, Próteses e Meios Auxiliares de Locomoção (OPMs); possibilitando que a oferta dessas tecnologias assistivas seja realizada a partir das características individuais e das necessidades funcionais de cada pessoa, o que, sem dúvida, é condição para que seu uso represente maior autonomia e melhor qualidade de vida aos seus usuários.

O brevíssimo panorama sobre a Rede de Cuidados à Saúde da Pessoa com Deficiência, traçado acima, permite afirmar que a atual política avança em várias direções e vai ao encontro do aprimoramento do SUS. Avança na universalidade, pois qualifica e amplia muito o acesso à saúde das pessoas com deficiência; avança na equidade, porque permite tratar diferenças e especificidades como tais, por meio das linhas de cuidado e da construção de projetos terapêuticos singulares, que partem da escuta aos contextos locais de saúde e às necessidades concretas das pessoas com deficiência; avança também na integralidade, que é 
sustentada na política pelas ações conjuntas entre os componentes da atenção, gerando sinergia e transversalidade entre pontos de atenção da Rede, cuja articulação também deve se orientar pelos contextos de vida e de saúde, bem como pelas necessidades concretas das pessoas com deficiência.

Entretanto, universalidade, equidade, integralidade... ganharão densidade se os cuidados às pessoas com deficiência forem entendidos como algo que nasce e se sustenta no conjunto das relações sociais, na circulação das diferenças, na pertença social, no enfrentamento de estigmas e de preconceitos, que ainda afetam essa população. Claro que esse é um desafio do conjunto da sociedade brasileira, mas para o qual o campo da saúde pode e deve colaborar.

Por isso mesmo, no âmbito da Rede de Cuidados à Saúde da Pessoa com Deficiência, parece promissor produzir saúde na alteridade, isto é, na relação com as diferenças, colocando-as em contato com as dinâmicas e desafios do SUS, trazendo as pessoas com deficiência, de fato, para dentro do sistema, para que possam exercer e reivindicar seus direitos como cidadãos que são.

Nesse sentido, a nova Rede quer, também, colaborar com a superação de visões que privilegiem o reconhecimento da pessoa com deficiência, exclusivamente, pela lógica bioidentitária; aquela que é dada pela identificação de uns com os outros a partir da condição biológica. Se marcas biológicas (raça, sexo, deficiência...), por um lado, favoreceram a organização social e a luta por direitos, por outro lado, no caso das deficiências e no âmbito de uma sociedade segregadora como a nossa, mantiveram o estigma da deficiência e podem reforçar a tendência ao isolacionismo social, transformando a luta por direitos em conquista jurídico/formal, e não em inclusão cidadã, a partir da qual as diferenças (inclusive as biológicas) devem conviver no jogo social.

Por fim, embora a nova Rede tenha sido bem recebida pelos movimentos sociais das pessoas com deficiência, bem como pelos estados e municípios brasileiros, seu desenvolvimento, aprimoramento e fortalecimento precisam ser estudados e debatidos mais amplamente também no campo acadêmico. A expansão do debate acadêmico pode contribuir para qualificar a formação de profissionais para nova política e, ao mesmo tempo, ativar a necessária interlocução da Rede com outras áreas de conhecimento, além daquelas ligadas mais diretamente à reabilitação, uma vez que as problemáticas implicadas com as deficiências afetam e são transversais a muitas outras áreas de conhecimento. Fica aqui o convite e uma espécie de chamamento público a esse importante debate.

\section{Colaboradores}

Os autores participaram, igualmente, de todas as etapas de elaboração do artigo. 